\title{
Improving IT Infrastructure Capabilities through IT Personnel Capabilities: Thai Industry of Software and Services
}

\author{
Waraporn Jirachiefpattana ${ }^{1 *}$ and Nachanok Bonmanit ${ }^{2}$ \\ 'School of Applied Statistics, National Institute of Development Administration, Bangkok, Thailand; \\ waraporn@as.nida.ac.th \\ 25iam Systems Development Ltd, Bangkok, Thailand; asakuraking@hotmail.com
}

\begin{abstract}
Objectives: This research aims to find which capability of IT personnel influence on IT infrastructure capability, especially the enterprise software and the mobile application software firms doing business in Thailand. Methods/Statistical Analysis: We collected data from project managers and users of 96 participated firms by employing questionnaires which contained the constructs borrowed from the study of Fink and Neumann. Each construct was validated by Cronbach alpha coefficient. In order to reduce bias, each questionnaire required responses from 3 persons per a firm. Then the mean of responses for each questionnaire of a firm was calculated and used as the data for our research. To analyze data, we employed the stepwise regression analysis to determine which competences of IT personnel have impact on the capability of IT infrastructure. Before utilizing the stepwise regression analysis, multicollinearity must be tested: the Variance Inflation Factor (VIF) and the Condition Index (CI). Findings: Technical and business capability of Information Technology personnel affect IT infrastructure capability in the overall Thai software industry and mobile application software firms. In case of enterprise software firms, IT infrastructure capability is influenced by only business capability of IT personnel. Application/Improvements: These findings suggest that human resource policies, training and organizational development programs of these firms can be adjusted to reach the best fitting composition of personnel for the achievement of the services. In addition, universities can utilize the outputs from this study to adapt graduate programs to serve the requirements of IT providers.
\end{abstract}

Keywords: Enterprise Software, Information Technology Infrastructure Capability, Information Technology Personnel Capability, Mobile Application Software, Thai Industry of Software and Services

\section{Introduction}

Now a day, business environment has been changed rapidly. Business has to manage it effectively, to escape from unknown threats and to invest in an emerging business. IT investment can help large and small firms to drive changes and improve operation, production, including performance of business ${ }^{1}$. In this regard, Thai firms also encounter and follow the same situation and footpath as others by employing IT providers. This trend has remarkably increased. In 2009, Thailand Development Research Institute (TDRI) surveyed software market and software services financial supported by Software Industry
Promotion Agency (Public organization). The results showed that the growth rate was $10.1 \%$ and its value was 29,418 million THB. The predictions in 2010 were $17.2 \%$ and 34,481 million THB, respectively. The survey covered 4 categories of software which were enterprise software, mobile application software (not include games on mobile phones), embedded systems and other software ${ }^{2}$.

Improvement of the performance of the businesses in this software industry depends on resources: IT infrastructure, personnel, organizational capital and the relationship between customers and suppliers $\frac{3-5}{}$. As the result, these firms need to leverage their resources in order to increase not only the organizational performance

*Author for correspondence 
but also the competitive advantages. According to the previous research $\frac{6,7}{7}$, IT infrastructure capability is the foundation of IT capability of an organization which affects the organizational outcomes.

Although, ${ }^{8}$ studied the influence of IT personnel capabilities on IT infrastructure capabilities, their research did not include the software industry. In addition, IT outsourcing in Thailand has continuously increased. These allowed us to question what capabilities of IT personnel who are working in software industry affect on IT infrastructure capability. The research focused on only software industry that produced or provided services related to enterprise software and mobile application software. The results from our study provide recommendations for the software firms and academic to enhance IT infrastructure capability and academic curriculums.

\section{Background and Research Model}

\subsection{IT Infrastructure Capabilities}

IT infrastructure includes a set of shared technical components and IT services that enable the effective use

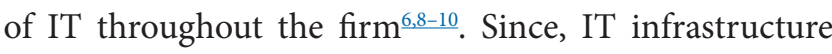
services play an important role, ${ }^{11}$ proposed that necessary IT infrastructure services should include 3 elements which were IT components, IT personnel infrastructure and shared IT services. The results of their study indicated that in achieving business goals one contributor was 23 infrastructure services. The services were categorized into two groups which were 5 key services of IT infrastructure and other 18 IT infrastructure facilities. Two years later ${ }^{10,12}$ developed the structure of IT infrastructure services extended from the work in $1997^{11}$. They grouped 23 IT infrastructure services into 8 categories.

Regarding to e-business, ${ }^{13}$ proposed a new IT infrastructure services framework to handle with relationship between the organizations and stake holders. The services included 70 and grouped into 10 . These groups were managing channel, managing security and risk, communications, managing data, application infrastructure, IT facilities management, IT management, IT architecture and standards, IT education and IT R\&D. These 10 groups were employed by Fink and Neumann ${ }^{-}$as shown in Table 1 to examine the relationship between competences of IT personnel and capabilities of IT infrastructure, including association between IT-dependent organizational

Table 1. IT infrastructure capability measures

\begin{tabular}{|c|c|}
\hline Measures & Descriptions \\
\hline Channel management & $\begin{array}{c}\text { Providing a variety of channel management services: Web sites, e-mail, call center, interactive } \\
\text { voice response, wireless devices }\end{array}$ \\
\hline $\begin{array}{l}\text { Security and risk } \\
\text { management }\end{array}$ & $\begin{array}{l}\text { Offering a diversity of services for managing risk and security in order to protect the firm's brand } \\
\text { reputation, data and equipment: security policy, firewall, encryption, disaster planning }\end{array}$ \\
\hline Communication services & $\begin{array}{c}\text { Arranging a variety of communication services: network linking all points within firms, intranet, } \\
\text { extranet, groupware }\end{array}$ \\
\hline Data management & $\begin{array}{l}\text { Offering an assortment of services for managing data: data free from applications, unified data } \\
\text { warehouse, large storage, knowledge management }\end{array}$ \\
\hline Application infrastructure & $\begin{array}{l}\text { Providing a diversity of application infrastructure services: central management of application, } \\
\text { middleware, mobile and wireless applications, ASP, }\end{array}$ \\
\hline IT facilities management & $\begin{array}{l}\text { Arranging various services for managing IT facilities: larger size of processing/mainframe, server } \\
\text { farms, shared environment for systems development }\end{array}$ \\
\hline IT management & $\begin{array}{l}\text { Providing various services for IT management: developing IS plan, managing IS project, } \\
\text { negotiating with suppliers and outsourcers, level agreement of services }\end{array}$ \\
\hline IT architecture and standards & $\begin{array}{l}\text { Offering a diversity of IT architecture and standards services: specify and enforce architecture and } \\
\text { standards for technologies, communications, data and applications }\end{array}$ \\
\hline IT education & $\begin{array}{c}\text { Facilitating an assortment of services for IT education: training how to use IT, managing, learning } \\
\text { to create benefit from employing IT }\end{array}$ \\
\hline $\begin{array}{l}\text { IT research and development } \\
\text { (IT R\&D) }\end{array}$ & $\begin{array}{l}\text { Providing a variety of services for IT research and development: specify and asses new } \\
\text { technologies according to business goals, assess offers for new IS applications }\end{array}$ \\
\hline
\end{tabular}

Source ${ }^{8}$ 
agility and IT infrastructure. The results of their research illustrated that IT infrastructure services were positively affected by technical and behavioral capabilities of IT personnel. In addition, IT-dependent organizational agility was also influenced by capability of IT infrastructure.

Another direction of research on IT infrastructure services is the flexibility as it provides ability to organizations to use IT infrastructure for gaining competitive advantages. In ${ }^{14}$ presented a construct to measure IT infrastructure flexibility. This construct contained 8 dimensions divided into 2 groups. The first group was technical IT infrastructure which involved IT connectivity, application functionality, IT compatibility and data transparency. The second group was called human IT infrastructure which contained knowledge related to technology management, business, management and technique.

\subsection{IT Personnel Capability}

In the past, IT did not consider as a strategic tool for business competition. The major task of IT personals during this time period was technical supports. Therefore,

Table 2. IT personnel capability measures

\begin{tabular}{|c|c|}
\hline Measures & Descriptions \\
\hline $\begin{array}{c}\text { Technical } \\
\text { Capability }\end{array}$ & $\begin{array}{c}\text { Multiple structured programming, CASE } \\
\text { methods, or tools } \\
\text { Distributed processing or computing } \\
\text { Network management and maintenance } \\
\text { Developing Web-based applications } \\
\text { Data warehousing, mining, or marts }\end{array}$ \\
\hline $\begin{array}{c}\text { Self-directed and proactive } \\
\text { Capability }\end{array}$ & $\begin{array}{c}\text { Able to plan, organize, and lead project } \\
\text { Able to plan and perform work in cooperative } \\
\text { environment } \\
\text { Well perform in cross-functional groups, } \\
\text { pointing business problems } \\
\text { Able to provide other IT services regardless of } \\
\text { Business } \\
\text { their primary knowledge area because of cross- } \\
\text { training }\end{array}$ \\
$\begin{array}{c}\text { Have knowledge about the key success factors } \\
\text { Learn new information technologies } \\
\text { Catch up new information technologies } \\
\text { Well align the IT strategies within the business } \\
\text { strategies } \\
\text { Understand the strategies and plans of } \\
\text { organization } \\
\text { Understand functions of organization }\end{array}$ \\
\hline
\end{tabular}

Source $^{8}$ technical skills were more important for IT programmers and systems analysts than managerial and business skills. In the 1980s, IT has been viewed as a resource that organizations could strategically use to gain competitive advantages ${ }^{15}$. The changing in the perception of the value of IT resulted in changing the skills required by IT personnel. During this time, although technical skills remained important, managerial knowledge was needed for programmers and systems analysts to promote to managerial position $\frac{16-18}{}$. Moreover, ${ }^{19}$ found that strong business and communication skills for entry level position were more necessary than technical skills.

The study from the last two decades has been consistent in reporting that IT professionals must have variety of skills which were management, business, interpersonal and technical expertise ${ }^{8,15,20}$. In the area of IT infrastructure, IT personnel capabilities were cited as a component of IT capability. Furthermore, they also have the relationship with IT infrastructure capabilities. In ${ }^{15}$ investigated the relationship between IT personnel skills and two constructs: Information systems infrastructure flexibility and competitive advantage. The constructs of the skills were brought from a study of ${ }^{20}$. These skills consisted of technology management, business skills, interpersonal skills and technical skills. In ${ }^{8}$ also used IT personnel capabilities studied by ${ }^{15}$ to assess their influence on IT infrastructure capabilities. The measures showed in Table 2.

In the context of IT outsourcing, ${ }^{12}$ sought to understand the type of skills that were most critical for clients and providers. The results indicated that clients emphasized on technical skills for new hires more than IT providers. While providers emphasized on project management skills, relationship skills and global delivery skills, clients viewed business skills such as business process reengineering and change management were important. In

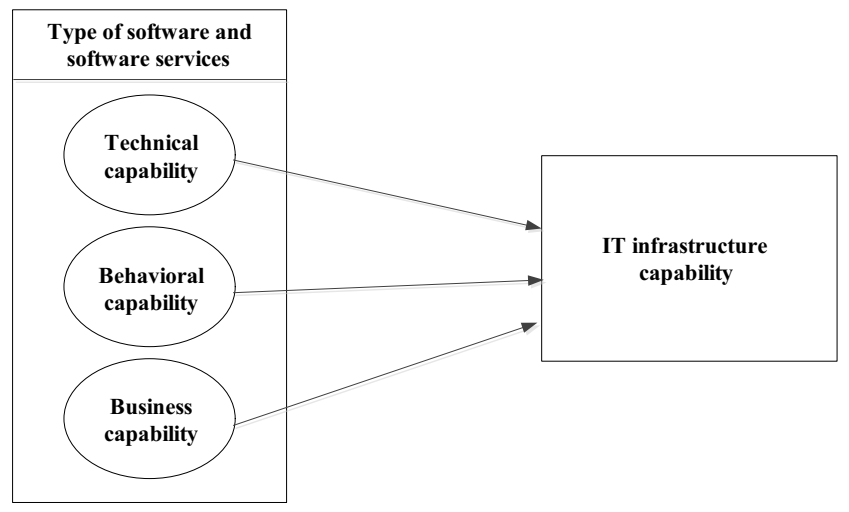

Figure 1. Research model. 
summary, IT providers focused on non-technical skills at the same time technical skills were considered as a foundation to entry to IT positions.

\subsection{Research Model}

The objective of this research and information from the above literature direct us to develop a research model that associates the critical IT personnel capabilities with IT infrastructure capability, especially Thai software industry as illustrated in Figure 1. To develop the effective and efficient IT infrastructure capability, IT firms require IT personnel who have not only technical capability but also behavior and business skills. The technical skill is necessary for providing infrastructure services. Because role of IT in organization is extended, therefore, the behavior capability provides skills and knowledge for working with other people and managing projects. Lastly, business skill has been asserted as an important skill to help IT personnel to align IT with business strategies. Regarding to the above research review, measuring IT personal capability and IT infrastructure capability are not too different. The measures developed by ${ }^{\underline{8}}$ broadly cover related elements stated in the literature. As the result, we decided to employ their model in our research.

\section{Research Method}

The aim of our research is to investigate which capabilities of IT personnel have an effect on the area of IT infrastructure capability regarding to the types of software firms in Thai software industry which are enterprise software and mobile application software firms. To find out the answers, we developed two questionnaires to collect the relevant data. The first questionnaire was designed to capture the level of IT personnel capabilities assessed by IT managers or IT project managers whereas the second questionnaire was developed to collect the opinion of users related to the services of IT infrastructure. To assess the level of the respondent's opinion, we employed five Likert scales. Before starting data collection process, these questionnaires were pretested with the target organizations. For each questionnaire, there were 40 persons involved in the pretest. Cronbach alpha coefficient of each construct was calculated and they indicated that the questionnaires were reliable.

According to the final report about software market and software services ${ }^{2}$, the total number of firms in Thai software industry which were performing their businesses was 866 . Due to known population, the sample size was 274 with $95 \%$ confident $^{22}$. Then, 300 questionnaires were sent out and returned questionnaires were 96 which equal $32.0 \%$. In order to reduce bias, each questionnaire required responses from 3 persons per a firm. Then the mean of responses for each questionnaire of a firm was calculated and used as the data for our research.

With respects to our research questions, we employed the stepwise regression analysis to determine which competences of IT personnel have impact on the capability of IT infrastructure. In order to utilize the stepwise regression analysis, multicollinearity must be tested. Generally, there are two statistics for testing the collinearity: The Variance Inflation Factor (VIF) and the Condition Index (CI). In this study, all VIFs and CIs are not more than the threshold levels ${ }^{23}$ as in Table 3. Together, the results of these tests indicate that multicollinearity does not appear in our research data.

\section{Findings}

\subsection{General Data}

The profiles organizations and respondents of both type of software business are similar. According to 96 contributed software organizations, there were 58 (60.41\%) firms doing their business related to enterprise software while there were 38 (39.59\%) mobile application software. The following presentation orderly show the percentages of enterprise software firms and mobile application software organizations in the parenthesis.

Most of the software firms employed IT personnel from between $21-30$ persons $(48.28 \%, 55.26 \%)$ and revenue was more than 10 million THB (63.79\%, 60.53\%). With regard to the profile of IT manager/IT project manager, most respondents were female $(57.47 \%, 50.88 \%)$, aged from 31 to 40 years old $(53.45 \%, 50.88)$ and work experience related to IT ranged from 6 to 10 years (51.15\%, 52.63\%). Differently, most IT manager/IT project of enterprise software firms received bachelor degree (50.57\%) while master degree (51.75) was the education level of respondents from mobile application software firms. Additionally, most IT users who involved in this research were female, aged from 21 to 30 years old and got bachelor degree. They had experience related to IT less than 6 years and hold officer positions.

The average scores of IT personnel capability and IT infrastructure capability reveal that IT managers/IT project managers and IT users of both type of software firms 
considered the capabilities of IT personnel in a similar pattern. Every capability is almost equally important which ranged from 3.83 to 3.89 . At the same time, users of IT infrastructure services also believed the IT infrastructure is capable at high level regardless of the type of software business.

\subsection{Influence of the IT Personnel Capabilities of Software Firms on IT Infrastructure Capability}

Table 3 presents the results from the regression analysis. In general, the result indicates that IT infrastructure capability of Thai software firms is significantly affected by technical and business capabilities of IT personnel $(b=4.184$, $p=.000, b=4.321, p=.000$, respectively). The regression model is also significant and can predict IT infrastructure capability by approximately $64.3 \%\left(R^{2}=.643, F=83.859\right.$, $p=000)$. According to our research questions, the data of the enterprise software firms were analyzed and point out that IT infrastructure capability is significantly predicted by only business capability $(b=.816, p=.000)$ and the ability of explanation is at $62.3 \%\left(R^{2}=.623, F=92.427, p=\right.$ 000 ). With regard to the mobile application software firms, the results tell that technical and business capabilities significantly influence on IT infrastructure capability $(b=$ $.671, p=.000, b=.238, p=.028$, respectively). Moreover, the regression model is significant and can explain the influence about $75.9 \%\left(R^{2}=.759, F=54.972, p=000\right)$.

\section{Conclusions and Implications}

This study sought to identify the capabilities of IT personnel of Thai software firms affecting IT infrastructure capability. According to the research questions, in general, IT infrastructure capability is affected by technical and business skills of IT personnel of Thai software industry. As well, both capabilities also influence on the services of IT infrastructure of mobile application software firms. Contrary to the finding of these cases, business capability is only one factor affected on IT infrastructure of enterprise software firms.

The results from the stepwise regression analysis in this study held one difference from the literature. The study finds that behavioral capability of IT personnel does not influence on IT infrastructure capability of Thai software firms. This finding contrasts with the results specified by previous researches. One explanation for the lack of influence might be because of the perceptions of Thai IT managers/IT project managers. These people are likely to have technical backgrounds and may not recognize the value of this skill.

The findings of this study can contribute to a better understanding of how to improve services of IT infrastructure in Thailand through these IT personnel skills and knowledge. This information describing the skill and knowledge of Thai IT professionals can provide the executive of IT providers to increase the successful functioning of IT infrastructure capability, according to the type of their businesses. Human resource policies, training and

Table 3. Influence of the IT personnel capabilities of software firms on IT infrastructure capability

\begin{tabular}{|c|c|c|c|c|c|c|c|c|}
\hline IT personnel capabilities & b & SE b & $\beta$ & $\mathrm{t}$ & Sig. & Tolerance & VIF & CI \\
\hline \multicolumn{9}{|l|}{ All firms } \\
\hline constant & 5.762 & 2.562 & & 2.249 & 0.27 & & & \\
\hline Technical capability & 4.184 & .900 & .430 & 4.646 & .000 & .447 & 2.235 & 17.600 \\
\hline Business capability & 4.321 & .933 & .426 & 4.631 & .000 & .447 & 2.235 & 26.640 \\
\hline \multicolumn{9}{|c|}{$\mathbf{R}=802, \mathbf{R}^{2}=.643, \mathbf{R}_{\text {adj }}^{2}=.636, \mathbf{S E E}=3.00524, \mathbf{F}=83.859$, Sig. $=.000$} \\
\hline \multicolumn{9}{|l|}{ Enterprise software firms } \\
\hline constant & .680 & .333 & & 2.038 & .046 & & & \\
\hline Business capability & .816 & .085 & .789 & 9.614 & .000 & 1.000 & 1.000 & 15.832 \\
\hline \multicolumn{9}{|c|}{$\mathbf{R}=.789, \mathbf{R}^{2}=.623, \mathbf{R}_{\text {adj }}^{2}=.616, \mathbf{S E E}=.31958, \mathbf{F}=92.427$, Sig. $=.000$} \\
\hline & .387 & .344 & & 1.125 & .268 & & & \\
\hline Technical capability & .671 & .104 & .694 & 6.468 & .000 & .599 & 1.669 & 18.625 \\
\hline Business capability & .238 & .104 & .246 & 2.292 & .028 & .599 & 1.669 & 22.745 \\
\hline \multicolumn{9}{|c|}{$\mathbf{R}=871, \mathbf{R}^{2}=.759, \mathbf{R}_{\text {adj }}^{2}=.745, \mathbf{S E E}=.24049, \mathbf{F}=54.972$, Sig. $=.000$} \\
\hline
\end{tabular}


organizational development programs can be adjusted to reach the best fitting composition of personnel for the achievement of the services.

Furthermore, universities can utilize the outputs from this study to adapt graduate programs to serve the requirements of IT providers. The needs of IT providers will likely become more important as trend of employing outsources continually increases. As well, enhancement of existing curriculum or creation of new programs for experienced IT personnel may be possible. In addition, individuals may use the results to seek positions or career development that they prefer.

Lastly, this research has several limitations. First, a lack of qualitative data has resulted in an inadequacy of rich information to explain situations due to the exploratory research. Therefore, the findings were derived in the form of statistics. Second, the samples of this research were IT outsourcing companies in Thailand. Consequently, any use of these results should be undertaken cautiously, even by other Thai IT organizations, because the organizational settings are different. In order to further explain why and how capabilities of IT personnel influence on IT infrastructure capability, researchers should strive to obtain qualitative data. Hence, in the future, in-depth interviews would be helpful.

\section{Reference}

1. Lu Y, Ramamurthy K. Understanding the link between ten Information Technology capability and organizational agility: An empirical examination. MIS Quarterly. 2011Dec; 35(4):931-54.

2. The survey of the software and software services market. Software Industry Promotion Agency (SIPA), Thailand Development Research Institute (TDRI); Bangkok. 2009.

3. Feeny D, Lacity M, Willcocks LP. Taking the measure of outsourcing providers. MIT Sloan Management Review. 2005 Mar; 46(5):41-8.

4. Jirachiefpattna W. Using individual values of Information Technology professionals to improve software development management practices in Thailand. Asian Academy of Management Journal. 2015; 20(1):49-69.

5. Lahiri S, Kedia BL. The effects of internal resource and partnership quality on firm performance: An examination of Indian BPO providers. Journal of International Management. 2009 Jun; 15(2):209-24.

6. Bharadwaj AS. A resource-based perspective on Information Technology capability and firm performance: An empirical investigation. MIS Quarterly. 2000 Mar; 24(1):169-96.

7. Stoel MD, Muhanna WA. IT capabilities and firm performance: A contingency analysis of the role of industry and
IT capability type. Information and Management. 2009 Apr; 46(3):181-9.

8. Fink L, Neumann S. Gaining agility through it personnel capabilities: The mediating role of it infrastructure capabilities. Journal of the Association for Information Systems. 2007 Aug; 8(8):440-62.

9. Byrd TA. Information Technology, core competencies and sustained competitive advantage. Information Resources Management Journal. 2001 Apr; 14(2):27-36.

10. Broadbent M, Weill P, Neo BS. Strategic context and patterns of IT infrastructure capability. The Journal of Strategic Information Systems.1999 Jun; 8(2):157-87.

11. Broadbent M, Weill P. Management by maximum: How business and IT managers can create IT infrastructures. Sloan Management Review. 1997 Apr; 38(3):77-92.

12. Broadbent $M$, Weill $\mathrm{P}$, Clair D. The implications of Information Technology infrastructure for business process redesign. MIS Quarterly. 1999 Jun; 23(2):159-82.

13. Weill P, Subramani M, Broadbent M. Building IT infrastructure for strategic agility. MIT Sloan Management Review. 2002 Oct; 44(1):57-65.

14. ByrdTA, TurnerDE. Measuring the flexibility of Information Technology infrastructure: Exploratory analysis of a construct. Journal of Management Information Systems. 2000; 17(1):167-208.

15. Byrd TA, Turner DE. An exploratory analysis of the value of the skills of IT personnel: Their relationship to IS infrastructure and competitive advantage. Decision Sciences. 2001 Mar; 32(1):21-54.

16. Cheney PH, Lyons NR. Information systems skill requirements: A survey. MIS Quarterly.1980 Mar; 4(1):35-43.

17. Harrison W, Springer D. A software systems management MBA option. Data Base. 1985; 16(2):19-23.

18. Jenkins GH. Education requirements for the entry level business systems analysts. Journal of Systems Management. 1986 Aug; 36(3):30-3.

19 Green GI. Perceived importance of system analysts' job skills, roles and non-salary incentives. MIS Quarterly. 1989 Jun; 13(2):115-33.

20. Lee DMS, Trauth EM, Farwell D. Critical skills and knowledge requirements of IS professionals: A joint academic/industry investigation. MIS Quarterly. 1995 Sep; 19(3):313-40.

21 Hawk S, Kaiser KM, Goles T. Bullen CV, Simon JC, Beath CM, Gallagher KP, Frampton K. The Information Technology workforce: A comparison of critical skills of client and service providers. Information Systems Management. 2012 Jan; 29(2):2-12.

22 Yamane T. Statistics: An introductory analysis. New York: Harper and Row Publications; 1973.

23 Hair JF, Anderson RE, Tatham RL, Black WC. Multivariate data analysis. 5th ed. New Jersey: Prentice Hall; 1998. 